\title{
EL TRAMPANTOJO FRANCÉS DE LA ACCESIBILIDAD: LA VIVIENDA EVOLUTIVA
}

The French trompe-I'œil of accessibility: evolutionary housing

DOI: http://dx.doi.org/10.15304/dereito.29.Ext.6579

\author{
AlejandRa Boto Álvarez \\ Profesora Titular de Derecho Administrativo \\ Universidad de Oviedo \\ ORCID ID: https://orcid.org/0000-0002-7616-1236 \\ botoalejandra@uniovi.es
}

\section{RESUMEN}

La acción pública francesa en materia de vivienda ha sido una constante legislativa en los últimos tiempos, y su último episodio es la llamada Ley ELAN.

Lo que aquí se pretende analizar es la génesis, alcance y contenido de la primera parte de su artículo 64, que dispone, con el fin de reducir los costes de construcción, que sólo el $20 \%$ de los inmuebles de viviendas tendrán que ser accesibles para personas con discapacidad. El resto bastará con que sean alojamientos "evolutivos", que permitan en su caso alcanzar la accesibilidad a través de obras sencillas. La medida parece claramente regresiva y plantea para su aplicación toda una serie de interrogantes de interés que se tratarán de presentar.

Se abordará de forma crítica el impacto de este precepto, analizando su tramitación parlamentaria, particularmente agitada, y su posterior validación por el Consejo Constitucional.

Palabras clave: Accesibilidad; viviendas adaptadas; igualdad; discapacidad motriz; envejecimiento.

\section{ABSTRACT}

French public action in the field of housing has been a constant legislative activity in recent times, and its latest episode is the so-called ELAN Act.

The aim of this paper is to analyse the genesis, scope and content of the first part of its Article 64. According to it, for reducing construction costs, only $20 \%$ of dwelling buildings will have to be accessible to disabled people. For the rest $80 \%$ it will be enough to be evolutionary housing, allowing, if necessary, to achieve accessibility through simple works. The measure seems clearly regressive and raises a whole series of interesting questions for implementation.

The impact of this precept is hereby critically addressed, as well as the treacherous parliamentary processing and subsequent Constitutional exam and validation.

Keywords:

Accessibility; adaptive housing; equality; physical impairment; ageing. 


\section{SUMARIO}

1. INTRODUCCIÓN. 2. LA ACCESIBILIDAD EN LOS EDIFICIOS DE VIVIENDAS DE NUEVA CONSTRUCCIÓN ANTES DE LA LEY ELAN. 3. LA ACCESIBILIDAD TRAS LA LEY ELAN. 3.1 PROYECTO DE LEY Y TRAMITACIÓN PARLAMENTARIA. 3.2 EL CONCEPTO DE VIVIENDA EVOLUTIVA. 3.2.1 EL VIAJE DE IDA (¿Y VUELTA?) DE LO EVOLUTIVO A LO ACCESIBLE: OBRAS SENCILLAS Y ACTUACIONES REVERSIBLES. 3.2.2 LA ACCESIBILIDAD COMO META DE LA EVENTUAL EVOLUCIÓN Y EL PERÍMETRO DE LA UNIDAD DE VIDA. 3.3 EL EXAMEN CONSTITUCIONAL DEL PRECEPTO. 4. CONCLUSIONES. BIBLIOGRAFÍA

\section{INTRODUCCIÓN ${ }^{1}$}

Más allá de su genuina preocupación por contar con un verdadero servicio público de alojamiento social ${ }^{2}$, la acción pública francesa sobre la regulación general de la vivienda ha sido una constante legislativa en los últimos tiempos, con gestos de vanguardia como la Loi $n^{\circ}$ 2007-290 du 5 mars 2007 instituant le droit au logement opposable (DALO). Esta norma constituyó todo un hito al garantizar el derecho a la vivienda a una serie de demandantes prioritarios con un reconocimiento del derecho en vía administrativa, tutelable también procesalmente ${ }^{3}$.

En el ámbito de la protección a las personas con discapacidad, el legislador francés ha preferido en general acciones transversales. La única gran normativa sectorial es la Loi no 2005-102 du 11 février 2005 pour l'égalité des droits et des chances, la participation et la citoyenneté des personnes handicapées ${ }^{4}$, cuya última modificación se acometió, de manera reciente,

\footnotetext{
1 El presente trabajo ha sido elaborado en el marco del proyecto de investigación de referencia IDI/2018/000219 correspondiente a una ayuda a organismos públicos de investigación para apoyar las actividades de grupos de investigación en el Principado de Asturias concedida por el Gobierno de este al grupo SPAG (Servicios Públicos, Administraciones y Garantías) que coordina el profesor Tolivar Alas en la Universidad de Oviedo.

${ }^{2}$ La existencia de un servicio social de vivienda en Francia se remonta a principios del siglo XX (con la Loi sur les habitations bon marché, du 11 juillet 1912), aunque ya en 1894 y 1906 se habían adoptado medidas legislativas en la dirección de asegurar la existencia de alojamientos económicos, dignos y salubres para los más desfavorecidos; aquellas, sin embargo, se habían apoyado sobre sociedades mercantiles privadas, mientras que la Ley de 1912 creó todo un sector público vinculado a la "vivienda barata" que no se limitó, a diferencia de lo ocurrido en otros países, entre ellos España, a promover o facilitar el acceso a la propiedad inmobiliaria individual a través por ejemplo de la subvención y el fomento fiscal del crédito hipotecario, sino también a celebrar arrendamientos protegidos de carácter social. Desde entonces, Francia ha mantenido una posición activa en pro de la consecución de un mercado inmobiliario adaptado a las necesidades de toda la población, con sucesivas políticas y medidas legislativas constantes. Entre las últimas reformas merece la pena citar las acometidas en virtud de la Loi $n^{\circ}$ 2013-61 du 18 janvier 2013 relative à la mobilisation du foncier public en faveur du logement et au renforcement des obligations de production de logement social y la Loi $n^{\circ}$ 2014-366 du 24 mars 2014 pour l'accès au logement et un urbanisme rénové. En ese contexto sorprende la adopción de medidas regresivas como las que se comentarán en el texto por la reciente Loi no 2018-1021 du 23 novembre 2018 portant évolution du logement, de l'aménagement et du numérique. Para una panorámica general sobre el contenido de esta Ley, que también rebaja los aspectos sociales de la vivienda en otros aspectos, puede verse mi comentario en el número 51 (2019) de la Revista General de Derecho Administrativo, y la bibliografía allí citada.

${ }^{3}$ No es de extrañar que ese texto normativo generase fuerte interés más allá de las fronteras galas. Entre los trabajos de corte comparado merece la pena citar los de N. FOULQUIER, "La naturaleza del derecho exigible a una vivienda", Revista institucional de la defensa pública de la Ciudad Autónoma de Buenos Aires, 16, 2018, pp. 40-50 o C. MIALOT, "Diez años de la Ley DALO (derecho a la vivienda exigible) en Francia y el contexto europeo", en VV.AA., La ley del derecho a la vivienda de Catalunya: diez años de vigencia. Balance y futuro, Thomson Reuters-Aranzadi, Cizur Menor, 2018, pp. 59-73.

${ }^{4}$ Que tuvo como precedente la Loi no 75-534 du 30 juin 1975 d'orientation en faveur des personnes handicapées.
} 
con ocasión de la Loi $n^{\circ} 2018-771$ du 5 septembre 2018 pour la liberté de choisir son avenir professionnel.

El artículo 41 de la Ley de 2005 reescribió en su momento el código de la construcción y la vivienda para configurar un régimen formalmente amplísimo en materia de accesibilidad 5 . En efecto, el artículo L. 111-76 pasó de prever que las viviendas, lugares de trabajo e instalaciones abiertas al público, en particular las escolares, universitarias y de formación, tenían que ser accesibles a las personas con discapacidad a disponer explícitamente que tenían que ser accesibles a todos, en particular a las personas con discapacidad, cualquiera que sea el tipo de esta, incluyendo específicamente las de tipo físico, sensorial, cognitivo, mental y psíquico. Se pasaba asimismo a mencionar expresamente que esta obligación cubría ya no sólo la disposición arquitectónica y el diseño de los espacios, sino también los equipamientos interiores y exteriores. Parece indudable que con la reforma se introdujo una visión extensiva de la accesibilidad, expandiendo el campo de aplicación de su obligación tanto en sentido material como personal.

Sin embargo, ninguna de esas obligaciones era absoluta. En la versión anterior a 2005, el artículo preveía que a través de un Decreto en Consejo de Estado se fijarían las modalidades de aplicación de lo dispuesto en él7. Tras la reforma, ese carácter circunstancial se acentuaría, por un lado porque el artículo L. 111-7 directamente pasó a excluir de su ámbito de aplicación a los propietarios que construyen o reforman un alojamiento para su propio uso, pero además porque pasó también a preverse que la aplicación de la regla de accesibilidad, pretendidamente general, tendría que hacerse en los casos y condiciones fijadas en los artículos siguientes del mismo código ${ }^{8}$. En esos artículos se contienen relevantes normas técnicas en función del tipo de inmueble, de entre los que aquí interesan los dedicados a vivienda en libre mercado. Hay también importantes remisiones al poder reglamentario.

Así las cosas, es posible, sin tocar el tenor del artículo L. 111-7 y por tanto sin variar la exigencia aparente de plena accesibilidad para todos, adoptar medidas regresivas modificando los artículos siguientes en la parte legisla-

\footnotetext{
${ }^{5}$ El acceso a los textos normativos, y también a las versiones vigentes en un momento determinado, puede realizarse a través del portal institucional https://www.legifrance.gouv.fr/

6 Ubicado en la sección tercera (Personnes handicapées ou à mobilité réduite), del capítulo primero (Règles générales), título primero (Construction des bâtiments), libro primero (Dispositions générales) en la parte legislativa del code de la construction et de l'habitation.

7 Literalmente el artículo disponía: Les dispositions architecturales et les aménagements des locaux d'habitation, des lieux de travail et des établissements et installations recevant du public, notamment les locaux scolaires, universitaires et de formation, doivent être tels que ces locaux et installations soient accessibles aux personnes handicapées. Les modalités d'application des dispositions du présent article sont fixées par décret en Conseil d'Etat.

${ }^{8}$ Literalmente: Les dispositions architecturales, les aménagements et équipements intérieurs et extérieurs des locaux d'habitation, qu'ils soient la propriété de personnes privées ou publiques, des établissements recevant du public, des installations ouvertes au public et des lieux de travail doivent être tels que ces locaux et installations soient accessibles à tous, et notamment aux personnes handicapées, quel que soit le type de handicap, notamment physique, sensoriel, cognitif, mental ou psychique, dans les cas et selon les conditions déterminés aux articles L. 111-7-1 à L. 111-7-3. Ces dispositions ne sont pas obligatoires pour les propriétaires construisant ou améliorant un logement pour leur propre usage. En 2014, y en virtud de la Ordonnance $n^{\circ}$ 2014-1090 du 26 septembre 2014 relative à la mise en accessibilité des établissements recevant du public, des transports publics, des bâtiments d'habitation et de la voirie pour les personnes handicapées, la remisión a los artículos siguientes se ampliaría, alcanzando hasta el L. 111-7-11, para cubrir nuevos artículos precisamente insertados en el código por esta Ordonnance, una suerte de legislación delegada.
} 
tiva del código ${ }^{9}$. Y eso es precisamente lo que ha venido a realizar la Loi $n^{\circ}$ 2018-1021 du 23 novembre 2018 portant évolution du logement, de l'aménagement et du numérique (conocida como Ley ELAN), cuyo artículo 64-I cambia el contenido del artículo L. 111-7-1 del código de construcción, dedicado a las edificaciones y viviendas unifamiliares de nueva construcción, con un alcance trascendental al introducir el concepto de "vivienda evolutiva". En las páginas que siguen se presentará esta modificación, que afecta únicamente a las viviendas no unifamiliares de titularidad privada. Con carácter previo, y tras las cautelas expuestas, también será necesario analizar de cerca el verdadero alcance de la accesibilidad antes de la Ley ELAN, a fin de evitar preconcepciones erróneas sobre los auténticos perfiles del régimen previo de las viviendas accesibles para todos.

\section{LA ACCESIBILIDAD EN LOS EDIFICIOS DE VIVIENDAS DE NUEVA CONSTRUCCIÓN ANTES DE LA LEY ELAN}

A pesar de la dicción del artículo L. 111-7, no todas las viviendas de nueva construcción en Francia eran realmente accesibles antes de la Ley ELAN, pues el artículo L. 111-7-1 contenía a continuación una deslegalización casi total en favor del reglamento para establecer las modalidades de tal accesibilidad. La regulación reglamentaria resultaba contenida principalmente en el propio código (artículo R* 111-18 y siguientes), desarrollado a su vez en el arrêté du 24 décembre 2015 relatif à l'accessibilité aux personnes handicapées des bâtiments d'habitation collectifs et des maisons individuelles lors de leur construction, orden firmada por los ministros competentes en materia de vivienda y de desarrollo sostenible ${ }^{10}$.

Conforme a ella, una vivienda es "accesible" cuando permite a un inquilino o visitante con discapacidad circular, ubicarse, comunicarse, acceder a locales y equipamientos y utilizarlos con la mayor autonomía posible (artículo R* 111-18-1). La orden que desarrolla estas previsiones establece por ejemplo que los recorridos exteriores a la vivienda deben presentar un revestimiento con contraste visual y táctil respecto al entorno para facilitar su detección, que deben existir cojinetes de descanso cuyas medidas también se disciplinan después de planos inclinados con un desnivel del $4 \%$ o superior, y dispone cuáles son las anchuras mínimas de pasillos, escaleras y demás dotaciones, además de la forma en que deben señalizarse ${ }^{11}$.

Ahora bien, según el artículo R* 111-18-2, en el caso de las edificaciones de vivienda colectiva, las exigencias técnicas concretas para la accesibilidad interior no son uniformes. En concreto, varían en función de si la vivienda

\footnotetext{
${ }^{9}$ Pero no directamente por vía reglamentaria, tal y como ha señalado el Consejo de Estado a instancia de la Asociación Nacional para la integración de las personas con discapacidad motriz, en decisión número 295382, de 21 de julio de 2009, que anuló por esta razón el décret $n^{\circ} 2006-555$ du 17 mai 2006 relatif à l'accessibilité des établissements recevant du public, des installations ouvertes au public et des bâtiments d'habitation. El texto de la decisión puede consultarse en https://www.legifrance.gouv.fr/affichJuriAdmin.do?idTexte=CETATEXT000020936104.

${ }_{10}$ La misma asociación citada en la nota precedente pretendió en su momento la anulación de esta orden dando lugar a un interesante pronunciamiento del Consejo de Estado (decisión número 397360, de 22 de febrero de 2018), que puede consultarse en https://www.legifrance.gouv.fr/affichJuriAdmin. do? oldAction = rechJuriAdmin\&idTexte $=$ CETATEXT000036637082\&fastReqId $=350515889 \&$ fastPos $=1$.

${ }^{11}$ No obstante, debe hacerse también constar que la obligación de accesibilidad se configura como una obligación de resultados, y así el mismo artículo $\mathrm{R}^{*}$ 111-18-1 del código prevé que el promotor de la obra sustituya esas exigencias técnicas concretas por otras "con el mismo efecto".
} 
se sitúa en planta baja o con servicio real o potencial de ascensor ${ }^{12}$, frente a si no es así. Sólo respecto de las primeras se garantizan (y ello únicamente respecto a la cocina, el salón, una habitación y un baño) las condiciones arquitectónicas que permitirían su pleno uso por una persona en silla de ruedas $^{13}$. Para el resto existen sólo unas normas mínimas respecto a anchura de los accesos y puertas ${ }^{14}$.

Formalmente todas las viviendas de un edificio colectivo de nueva construcción serían viviendas etiquetadas como "accesibles", pero una persona en silla de ruedas sólo podrá acceder a algunas (las de la planta baja o con posibilidad de tener ascensor) y ni siquiera en su totalidad. Además, incluso en estas viviendas el espacio que debería quedar libre para la maniobra puede ser modularmente ocupado para otros fines, siempre que se trate de intervenciones reversibles (artículo $\mathrm{R}^{*}$ 111-18-2.-III) de manera que ni siquiera dentro de este "subconjunto" de viviendas más accesibles estas lo son siempre de manera absoluta ${ }^{15}$.

Se trata pues, de una previsión de accesibilidad general que tiene dos divisiones, establecidas en función del tipo de discapacidad. En cualquier caso, en ninguna de ellas es universal, plena ni inmediata.

\section{LA ACCESIBILIDAD TRAS LA LEY ELAN}

Sin haber cambiado nada en la engañosa regulación expuesta sobre la accesibilidad, la Ley ELAN ha venido a reducir aún más su exigencia, al establecer que sólo existirá la obligación de que sean "accesibles" el $20 \%$ de las nuevas viviendas, bastando que el resto sean "evolutivas". Antes de analizar este concepto, y su posterior juicio constitucional, conviene situar la nueva regulación en contexto.

\subsection{Proyecto de Ley y tramitación parlamentaria}

Uno de los objetivos declarados de la Ley ELAN es que se construya "más, mejor y más barato"; de hecho, ese es el tenor de su título primero ${ }^{16}$. En línea con ello, y con el propósito de simplificar la construcción, el proyecto de Ley ${ }^{17}$ contenía en su artículo 18 la previsión de que sólo la décima parte de las viviendas de los edificios de nueva construcción (con el número mínimo de una) tendrían que ser accesibles, mientras que el resto serían evo-

\footnotetext{
12 Desde el 1 de enero de 2007 es necesario instalar un ascensor en aquellas partes de edificios colectivos con más de tres pisos de altura sobre la planta baja (artículo R* 111-5 del código). En desarrollo de la Ley ELAN se ha aprobado el décret no 2019-305 du 11 avril, que modifica ese artículo del código y dispone que para las obras que soliciten licencia a partir del 1 de octubre de 2019 la exigencia de la instalación de ascensor se rebaja a los edificios con más de dos pisos de altura sobre la planta baja.

13 Las medidas de referencia de la silla se recogen en el anexo I de la orden ministerial citada y son de $0,75 \mathrm{~m} \times 1,25 \mathrm{~m}$.

14 Y que admiten a su vez determinadas excepciones (artículos L. 111-18-3, L. 111-4-1 y R* 111-183 del código).

${ }^{15}$ Al respecto puede verse el análisis de J. RAYNAL, "Droit au logement et accessibilité du cadre bâti aux personnes handicapées", Acualité juridique. Droit immobilier, 3, 2019, en particular pp. 181 y 182. Los trabajos reversibles tienen en todo caso como límite que una persona con cualquier tipo de discapacidad pueda visitar la vivienda, y por tal se entiende que pueda entrar, circular y salir (pero nada se dice por ejemplo sobre acceder a cocina o baño).

${ }^{16}$ Y los cronistas de la Ley lo subrayan unánimente. Por todos, véase R. NOGUELLOU, "La Loi ELAN: présentation rapide des dispositions sur le logement", Revue française de droit administratif, 1, 2019, p. 30.

17 Todos los documentos de la tramitación parlamentaria, incluyendo la revisión en sede constitucional, se pueden consultar en la misma web institucional referenciada más arriba.
} 
lutivas, susceptibles de convertirse en accesibles mediante obras sencillas ${ }^{18}$. En la exposición de motivos se señalaba que esto se hacía para ajustarse a la demanda, al tiempo que se indicaba que una vivienda evolutiva era una vivienda accesible en gran parte, y susceptible de convertirse en totalmente accesible a través de obras sencillas ${ }^{19}$. Nótese que las expresiones no son exactamente idénticas; a estas alturas resulta evidente que "accesible" y "totalmente accesible" no son ni mucho menos la misma cosa, pues en el contexto francés existen distintos grados normativos de accesibilidad.

La preocupación por rebajar los costes de la construcción se ve corroborada por el estudio de impacto que acompañaba al proyecto, que afrontaba esta cuestión en términos cuantitativos, indicando que para una vivienda media, la superficie adicional que genera la obligación de accesibilidad a personas en silla de ruedas es de unos 8 metros cuadrados, principalmente localizados en el baño, y se cifraban las viviendas sujetas a esa obligación de accesibilidad en 160.000 al año (p. 112) ${ }^{20}$. Es un espacio, se señala, que daría más confort empleado en otras zonas de la vivienda, y se recuerda que la mayor parte de la población no necesita un nivel tal elevado de accesibilidad, pues el número de personas en silla de ruedas no alcanza al $2 \%$ de la población total (p. 110). De hecho, se indica a partir de datos de la Federación francesa de promotores inmobiliarios, en más de la mitad de las viviendas que se compran sobre plano y que por estar en planta baja o servidas de ascensor deberían ser accesibles para personas en silla de ruedas, los compradores hacen la adaptación modular reversible que permite el artículo R* 111-18-2.-III (p. 111).

La ponencia sobre el proyecto de Ley en la Comisión de Asuntos Económicos de la Asamblea Nacional entendía que las previsiones del mismo buscaban optimizar la relación entre accesibilidad y calidad en el uso de la vivienda. Censuraba abiertamente que casi todas las personas en silla de ruedas pretendan que las viviendas nuevas sean inmediatamente accesibles y considera que la noción de viviendas evolutivas permite una concepción más amplia de la adaptabilidad inmobiliaria, dando lugar a viviendas que tendrían una distribución interior que las haría no-accesibles de manera inmediata (en el sentido, se precisa, de no resultar conformes con las previsiones reglamentarias vigentes en la materia), pero que podrían serlo sin modificaciones que afecten a fluidos u obras mayores (p. 279 del informe de la ponencia). La Comisión proponía incluir en el artículo la previsión de que en cinco años desde la promulgación de la norma se evaluara el grado en que las viviendas de nueva construcción habían devenido evolutivas o accesibles, enmienda que fue aceptada y que dará lugar en el futuro a interesantes datos para el análisis.

Ante la Comisión se presentaron seis enmiendas idénticas de supresión del artículo, que hacían valer el retroceso en materia de inclusión que supondría, en unos términos que ya habían sido puestos de manifiesto por el Conseil national consultatif des personnes handicapées (CNCPH) en un in-

\footnotetext{
18 Literalmente: (...) un dixième de leurs logements, et au moins un logement, est accessible tandis que leurs autres logements, évolutifs, peuvent être rendus accessibles à l'issue de travaux simples. ${ }_{19}$ Literalmente: (...) créant la notion de logement « évolutif », c'est-à-dire accessible en grande partie et pouvant être rendu totalement accessible, par des travaux simples.

20 Esto es, viviendas en planta baja o en edificios de cuatro alturas o más.
} 
forme sobre el Anteproyecto emitido en el mes de marzo ${ }^{21}$. Se hacía ver a su vez que, ante una vivienda evolutiva en alquiler, seguramente un arrendador poco escrupuloso preteriría como inquilino a una persona con discapacidad motriz para evitar así las obras, aunque fueran menores, de adaptación. Se cuantificaban además las viviendas nuevas que cumplirían las reglas de accesibilidad para personas en silla de ruedas desde la construcción en tan solo 2.300 al año (p. 281).

Los ponentes y representantes ministeriales defendieron el mantenimiento del artículo apoyándose en que el proyecto contaba con un informe favorable del Consejo de Estado, lo que excluía de plano cualquier argumento de discriminación ${ }^{22}$. Sostenían que con la modificación propuesta se permitiría seguir obteniendo un $100 \%$ de viviendas accesibles, aunque sólo el $10 \%$ lo fuera desde la construcción (p. 282). Puede verse como el discurso político moldea más aún unos conceptos jurídicos concebidos ya de manera bastante laxa. A la hora de precisar el concepto de obras sencillas, se ponía como ejemplo el desplazamiento de tabiques (p. 282).

Durante un largo debate, que trascendió de la Comisión al Pleno, se manejó otro concepto, diferenciando entre las viviendas "adaptadas" y las viviendas evolutivas (pp. 282-283). La expresión no aparece en la Ley, y tampoco durante la tramitación parlamentaria llega a explicarse lo que parece obvio: que frente a la noción de vivienda evolutiva no se erige un único concepto de vivienda accesible, sino las dos dimensiones (un mínimo de accesibilidad en general/adaptación a sillas de ruedas) que antes se han expuesto. Frente a ello también se trató de despolarizar la discusión haciendo ver que la condición de vivienda evolutiva no tenía necesariamente que leerse en clave de discapacidad motriz y ligando la evolución en la configuración interna de la vivienda con la evolución vital y el envejecimiento (p. 284).

La Comisión de Asuntos Económicos del Senado aprobó por su parte elevar al $30 \%$ y a un umbral mínimo de 10 el número de viviendas accesibles frente a las evolutivas. La medida se presentó por el ponente como un "compromiso" ante las múltiples críticas vertidas frente al proyecto de Ley por parte de distintos organismos de defensa de las personas con diversidad funcional. Pero no se ofrece ulterior explicación del cálculo que puede haberse llevado a cabo para fijar esos números (p. 244 del informe de la ponencia). En esa tesitura, y fruto de los trabajos de la Comisión Mixta Paritaria las cifras quedaron finalmente fijadas en el $20 \%$ final, cantidad que no deja de parecer caprichosa. Que el porcentaje se aplique sobre la unidad "viviendas" sin tener en cuenta su superficie ha sido también criti-

\footnotetext{
${ }^{21}$ El documento puede consultarse en https://www.gouvernement.fr/sites/default/files/contenu/piecejointe/2018/04/avis cncph loi elan 150318.pdf. Se trata de un documento particularmente crítico con la fijación de cuotas de viviendas accesibles, que incide en la necesidad de ver la vivienda en el marco de relaciones sociales, de hábitat y medioambientales conectada con el derecho a la ciudad y que conminaba a ahondar en medidas de mayor accesibilidad general (ascensores, acceso sin obras a todas las piezas de la casa, cuestiones técnicas en cuartos de baño, etc.)

22 Es cierto que el Consejo de Estado había validado el proyecto, pero también lo es que había criticado considerablemente la falta de profundidad del estudio de impacto (par. 6). Al analizar en concreto la cuestión de la accesibilidad, el Consejo de Estado se manifestó proclive a que la modificación legal no agotara todos los aspectos técnicos relativos a lo evolutivo de las viviendas, a fin de no desplazar al poder reglamentario (par. 33). También recomendaba mayor claridad e inteligibilidad en la redacción (par. 34).
} 
cado por la doctrina23. A mayores, en la nueva redacción del artículo L. 1117-1 la previsión del mínimo de viviendas evolutivas se condiciona a "las características del edificio", inciso vago donde los haya que ya se contenía en el proyecto de Ley pero que pasó desapercibido para las Cámaras ${ }^{24}$.

Otro foco de discusión parlamentaria pivotó sobre el alcance del concepto de vivienda evolutiva. Se realizaron numerosas propuestas sobre la propuesta inicial del proyecto de Ley, que no contenía una definición concreta. Finalmente, la configuración quedó como se expondrá a continuación.

\subsection{El concepto de vivienda evolutiva}

Tal y como se viene explicando, una vivienda evolutiva se define ante todo por exclusión: es así una vivienda que no es "accesible", en el sentido de que no cumple con las reglas de accesibilidad del código de la construcción y la vivienda. Pero tras la tramitación parlamentaria, el concepto finalmente introducido en el artículo L. 111-7-1 del código por el artículo 64-I de la Ley ELAN también tiene elementos de necesaria verificación.

Se dice así que la concepción de la vivienda evolutiva debe permitir la redistribución de volúmenes que garantice la ulterior accesibilidad de la "unidad de vida" a través de "obras sencillas". Se considera evolutiva toda vivienda en la que se den dos circunstancias:

a) una persona con discapacidad debe poder entrar y salir de la vivienda, a través de un camino accesible hasta salón y urinario, donde las dotaciones y equipamientos deben ser accesibles;

b) la conversión en accesible de las piezas que componen la unidad de vida en la vivienda debe poder realizarse ulteriormente a través de obras sencillas.

La previsión resulta redundante en su segundo requisito, rozando lo tautológico, genera cierta perplejidad en el primero y descansa sobre dos conceptos jurídicos indeterminados trascendentales para su juego: la unidad de vida y las obras sencillas ${ }^{25}$.

\footnotetext{
${ }^{23}$ También suscitaba interrogantes la aplicación del porcentaje respecto al momento en que debe calcularse (permiso de obra o inspección posterior) dado que es habitual introducir durante la construcción modificaciones. Incluso una vez construido pueden hacerse divisiones de lotes susceptibles de afectar al porcentaje, y que desplazan la responsabilidad de su control por ejemplo hacia los notarios. Al respecto puede verse G. DURAND-PASQUIER, "L'incidence de la Loi ELAN sur les normes et les règles de la construction", Revue de droit immobilier, 1, 2019, pp. 8-16. A todo esto ha venido a arrojar luz el Decreto 305-2019 citado en la nota 12 supra, que aclara que debe existir una relación de equivalencia entre el tamaño medio de viviendas evolutivas y accesibles para una misma tipología de construcción.

${ }^{24}$ En el original se dispone: Des décrets en Conseil d'Etat, pris après avis du Conseil national consultatif des personnes handicapées, fixent les modalités relatives à l'accessibilité aux personnes handicapées prévue à l'article L. 111-7 que doivent respecter les bâtiments ou parties de bâtiments nouveaux. Ils précisent, en particulier : $1^{\circ}$ Les modalités particulières applicables à la construction de bâtiments d'habitation collectifs ainsi que les conditions dans lesquelles, en fonction des caractéristiques de ces bâtiments, 20 \% de leurs logements, et au moins un logement, sont accessibles tandis que les autres logements sont évolutifs. El resaltado es mío.

${ }^{25}$ Literalmente: La conception des logements évolutifs doit permettre la redistribution des volumes pour garantir l'accessibilité ultérieure de l'unité de vie, à l'issue de travaux simples. Est considéré comme étant évolutif tout logement dans les bâtiments d'habitation collectifs répondant aux caractéristiques suivantes: a) Une personne en situation de handicap doit pouvoir accéder au logement, se rendre par un cheminement accessible dans le séjour et le cabinet d'aisance, dont les aménagements et les équipements doivent être accessibles, et en ressortir ; b) La mise en accessibilité des pièces composant l'unité de vie du logement est réalisable ultérieurement par des travaux simples.
} 


\subsubsection{El viaje de ida ( ¿̇y vuelta?) de lo evolutivo a lo accesible: obras sencillas y actuaciones reversibles}

Como se ha apuntado, la previsión de la segunda letra del artículo reformado nada aporta con respecto al inciso que lo precede, dejando sin aclarar lo que deba entenderse por "unidad de vida", como espacio en el que la ulterior accesibilidad depende de unas obras simples, cuyo alcance tampoco se detalla. Cabe así plantearse si estas obras sencillas coinciden o no en esencia con las obras reversibles que el artículo R* 111-18-2.-III del código prevé que pueden hacerse sobre las viviendas accesibles a personas en sillas de ruedas cuando se compra el inmueble sobre plano ${ }^{26}$. De hecho, hay quien ha visto ese punto como el verdadero objetivo de la reforma. Se trataría así de invertir la secuencia lógica y las cargas, de manera que, en lugar de hacer que el comprador solicite del promotor la realización de obras reversibles para ocupar el espacio interior que permite la accesibilidad a una silla de ruedas porque prefiere ocuparlo de otra manera (cosa que según el estudio de impacto ocurre en un 50$70 \%$ de los casos), se posibilita directamente que la vivienda se construya en esas condiciones, siendo la obra sencilla el medio para conseguir la accesibilidad (en el $80 \%$ de los casos, pues el resto ya son directamente accesibles), y ello ahora a instancia de la persona con diversidad funcional que lo precise ${ }^{27}$.

Al no haberse modificado el artículo R* 111-18-2.-III del código, también cabe preguntarse si las obras modificativas reversibles pueden solicitarse afectando al umbral del $20 \%$ de viviendas accesibles; de suerte que en último caso el número de viviendas accesibles podría ser en realidad menor, porque sobre las inicialmente proyectadas los compradores solicitasen la realización de modificaciones reversibles ${ }^{28}$.

Huelga casi mencionar, por otra parte, que, dado que no se ha modificado el concepto normativo de accesibilidad, ese $20 \%$ de viviendas accesibles no tendría por qué ser necesariamente del grado especial de accesibilidad (el pensado para las personas en silla de ruedas). Es en esta clave donde se genera cierta perplejidad, por la similitud de la lógica empleada en el apartado a) del artículo para definir las viviendas evolutivas con la utilizada para identificar las viviendas accesibles con carácter general.

\subsubsection{La accesibilidad como meta de la eventual evolución y el perí- metro de la unidad de vida}

Retomando lo que se ha expuesto con anterioridad, cabe concluir que la diferencia entre una vivienda accesible en el grado general y una vivienda evolutiva es mínima, lo que explica la polarización de las críticas a la reforma en la perspectiva de las personas con discapacidad motriz, que son quienes verdaderamente podrán ver afectado el adecuado ejercicio de su derecho a la vivienda.

En efecto, una vivienda accesible que no se encuentre en planta baja y no pueda contar con ascensor es sin más una vivienda que tiene garantizada desde su construcción que las puertas y los lugares de tránsito permiten el paso a personas con discapacidad (artículo R* 111-18-2 del código). Eso también se tiene que dar en toda vivienda evolutiva de conformidad con la

\footnotetext{
${ }^{26}$ Vente en l'état futur d'achèvement (VEFA).

27 J. RAYNAL, op. cit., p. 183.

28 G. DURAND-PASQUIER, op cit., p. 12.
} 
nueva redacción del artículo L. 111-7-1.a); es más, a ello se añade la accesibilidad específica en las dotaciones de salones y urinarios.

¿Es entonces más garantista una vivienda evolutiva que la meramente accesible? Tal parece en una primera lectura, al considerarse en las viviendas evolutivas específicamente las dotaciones mencionadas; pero no puede olvidarse que la orden ministerial de 2015 que detalla las medidas técnicas concretas de la accesibilidad contiene no sólo previsiones relativas a los espacios exteriores y las puertas de entrada, salón y urinario, sino también prescripciones sobre anchura mínima de los pasos en todo el interior de la vivienda (artículo 11), condiciones técnicas sobre balcones, galerías o terrazas (artículo 14) y respecto a cuartos de baño, espacio más amplio que el urinario (artículo 15). En puridad estas no son medidas que tengan que respetar específicamente las viviendas evolutivas, aunque será difícil que si se proyectan de otra manera puedan convertirse en accesibles tan sólo a través de obras simples.

Así las cosas, el verdadero juego de la evolución hacia la accesibilidad no debería ser hacia la genérica, sino hacia la específica prevista para el desarrollo de una persona en silla de ruedas. A ello apunta también el empleo de la "unidad de vida" como medida del tránsito evolutivo hacia la accesibilidad.

$Y$ es que el concepto de unidad de vida no se define en el código de la construcción y la vivienda, y tampoco ha sido precisado por la Ley ELAN. Sólo aparece en la orden ministerial sobre accesibilidad, y concretamente en su artículo 13 , que se refiere a las viviendas situadas en planta baja o con ascensor; por tanto, las del grado de accesibilidad adecuado para las personas en silla de ruedas. Dado que la referencia a la unidad de vida fue introducida sin mayor explicación sobre su alcance en la sesión plenaria de la Asamblea Nacional y no resultó controvertida en el Senado, como si fuera de inteligibilidad automática, no cabe sino pensar que en la mens legislatoris la accesibilidad de destino a través de las obras sencillas no es la general, sino la específica.

Esto se ve confirmado por el hecho de que este aspecto tampoco estaba en la motivación el recurso de inconstitucionalidad planteado por un grupo de diputados que en esa sede contestaron, en cambio, la validez de la reducción al $20 \%$ del porcentaje de viviendas accesibles y la imprecisión del alcance de las "obras sencillas".

\subsection{El examen constitucional del precepto}

Según los diputados recurrentes, al reducir del 100 al 20\% la proporción de viviendas accesibles para personas con diversidad funcional en los edificios colectivos de vivienda nueva, el legislador habría vulnerado los derechos de las personas con movilidad reducida, y con ello infringido el preámbulo de la Constitución de 1946 (aún en vigor ${ }^{29}$ ) y el principio de igualdad ante la Ley. Los preceptos presuntamente vulnerados del preámbulo constitucional eran los relativos a la obligación nacional de asegurar al individuo y a la familia las condiciones necesarias para su desarrollo (par. $10^{30}$ ) y la garantía general de la protección de la salud, el reposo y el ocio (par. 1131).

\footnotetext{
${ }^{29}$ De conformidad con lo dispuesto por el Consejo Constitucional francés en su decisión n 71-44, de 16 de julio de 1971.

30 Literalmente: La Nation assure à l'individu et à la famille les conditions nécessaires à leur développement.

${ }^{31}$ En el original: Elle garantit à tous, notamment à l'enfant, à la mère et aux vieux travailleurs, la protection de la santé, la sécurité matérielle, le repos et les loisirs. Tout être humain qui, en raison
} 
Entre los argumentos que daban soporte al recurso se indicaba que las obligaciones derivadas de los referidos preceptos del preámbulo de la Constitución de 1946 lo son, según la jurisprudencia constitucional32, de "medios y no de resultados" (a diferencia como se ha visto de las medidas para conseguir la accesibilidad inmobiliaria). Para los recurrentes la reforma propuesta no suponía una mera elección de los medios, sino un atentado directo contra el mismo principio de accesibilidad.

Además, entendían que hacer descansar la concepción de la vivienda evolutiva en unas obras denominadas sencillas, que la normativa ni la jurisprudencia han definido, vulneraba el objetivo de accesibilidad e inteligibilidad de la Ley, de valor constitucional, y supone una renuncia excesiva del legislador a ejercer sus competencias constitucionales. Si el concepto no se precisa, su aplicación en la práctica será de geometría variable, apuntaban, vulnerándose con ello el principio de igualdad.

En su decisión no 2018-772, de 15 de noviembre, el Consejo Constitucional no estimó ninguno de esos motivos de impugnación ${ }^{33}$. Entiende en cambio que el hecho de rebajar la exigencia de accesibilidad de las viviendas de nueva construcción al $20 \%$ tal y como hace la Ley ELAN no supone una vulneración de la Constitución, sino que es ejercicio legítimo de la discrecionalidad que corresponde al legislador a la hora de poner en marcha el pacto de solidaridad nacional en favor de las personas con movilidad reducida, ponderado en este caso con atender a la adaptación de las viviendas a la diversidad y evolución de las necesidades de individuos y familias. Es cierto, se reconoce, que la Ley ELAN rebaja las exigencias en accesibilidad, pero lo hace imponiendo que todas las nuevas viviendas sean evolutivas, por lo que sigue manteniendo el compromiso con las personas con discapacidad y lo hace, según el Consejo Constitucional, con criterios que no son manifiestamente inadecuados ni vulneran el principio de igualdad (cons. 40).

El Tribunal afirma igualmente que el concepto de "obras sencillas" no es impreciso, y que según los debates parlamentarios se ha de entender por tales los trabajos que no afectan a la estructura, ni a la alimentación de fluidos, aire o electricidad (cons. 39). Sin ánimo de entrar en polémica y tras repasar todos los documentos oficiales disponibles sobre el devenir del proyecto de Ley, tal cosa sólo aparece en las observaciones del Gobierno ante el recurso de inconstitucionalidad, y en todo caso se trata de una fuente de dudoso valor jurídico. Hubiera parecido seguramente más ortodoxo reconocer en este punto la competencia suficiente del poder reglamentario para proceder a su detalle, tal y como en su momento había apuntado el Consejo de Estado.

\section{CONCLUSIONES}

Llegados a este punto es necesario concluir el análisis propuesto, sin que quepa evitar la sensación de que en realidad no se ha llegado al verdadero final. En efecto, aprobada la Ley ELAN quedaba esperar al desarrollo reglamentario del nuevo artículo L. 111-7-1 del código de la construcción y la vi-

de son âge, de son état physique ou mental, de la situation économique, se trouve dans l'incapacité de travailler a le droit d'obtenir de la collectivité des moyens convenables d'existence.

32 Decisión del Consejo Constitucional no 2003-483, de 14 de agosto.

33 Para un comentario detallado de la sentencia puede verse el trabajo de P. BATTISTINI, "La loi portant évolution du logement, de l'aménagement et du numérique, dite ELAN, à l'épreuve du Conseil constitutionnel", Les Petites Affiches, 19, 2019, pp. 7-10 
vienda para descifrar las condiciones evolutivas del nuevo parque de viviendas colectivas. El primer paso se acometió con el Decreto 2019-305, de 11 de abril, que ha introducido un apartado 3 en el artículo $R^{*}$ 111-18-2 del código indicando que los trabajos simples (que permiten hacer la vivienda evolutiva accesible en los términos del precedente apartado 2) son aquellos sin incidencia sobre los elementos estructurales ni sobre "ciertas" redes encastradas en muros, y remite a una futura orden ministerial la precisión de la naturaleza y condiciones de realización de tales obras ${ }^{34}$. Una vez más, encontramos remisiones normativas e imprecisiones recurrentes.

En las postrimerías de la aprobación de la Ley ELAN muchas fueron las voces que criticaron el retroceso en materia de accesibilidad física de la vivienda para personas con discapacidad. A título privado, pero también institucional, distintos actores vertían lamentos sobre una medida abiertamente regresiva, que haría pasar la construcción de nuevas viviendas en edificios colectivos de una regla previa de plena accesibilidad, a un máximo de $20 \%$ de viviendas accesibles por edificio de nueva construcción. Ello incluso fue soporte principal en el infructuoso recurso de inconstitucionalidad presentado por un grupo de diputados frente a la Ley.

Siendo ese carácter regresivo indudablemente cierto, lo que quedaba entonces silenciado es que la situación previa no era ni mucho menos tan idílica como podría parecer. Tras una configuración legislativa formal amplísima de la accesibilidad, se articulaba ya antes de la Ley ELAN un régimen a dos velocidades, y ni el mayor grado de accesibilidad previsto lo era en términos universales, absolutos o inmediatos.

Así las cosas, el lamento ante la nueva regulación debería ser doble, por replegarse sobre una situación de partida ya insuficiente. Pero la misma técnica normativa enrevesada que convertía una plena accesibilidad general en algo que no lo era tanto para todos, concatenando preceptos legales y reglamentarios de restricción, conduce a que al final los efectos de la regresión tampoco fueran los mismos para todos

Durante la tramitación parlamentaria de la norma, algunos diputados y senadores planteaban con un buenismo evidente, la necesidad de considerar en el debate toda diversidad funcional en el acceso a la vivienda, poniendo de manifiesto la existencia de un pujante lobby en representación de los derechos de las personas en sillas de ruedas que estaba monopolizando el análisis. Es este un planteamiento que peca de demagogia o de ignorancia del intrincado marco normativo previo y que, lejos de modificarse, se ha complicado.

Tal y como se ha puesto de manifiesto, y pese a su validación constitucional, el concepto legal de vivienda evolutiva resulta en parte tautológico, y lleva a que sus perfiles no puedan deslindarse del todo bien frente a la accesibilidad de menor grado, que venía siendo la aplicable a todas las viviendas situadas en edificios de hasta tres alturas, salvo las emplazadas en planta baja.

Se ha explicado cómo la única interpretación lógica es que la accesibilidad hacia la que han de poder evolucionar las nuevas viviendas es la más intensa, eso es, la prevista para el desenvolvimiento de una silla de ruedas.

\footnotetext{
${ }^{34}$ En el original: (...) à l'issue de travaux simples, c'est-à-dire sans incidence sur les éléments de structure et certains réseaux encastrés en cloisons. Un arrêté du ministre chargé de la construction précise la nature et les conditions de réalisation de ces travaux simples.
} 
Ello se ha visto confirmado con la aprobación del primer Decreto de desarrollo del artículo 64 de la Ley ELAN, que trata de precisar, pero sin conseguirlo del todo, los límites de la evolución. Rizando el rizo y de una forma un tanto sorprendente, esa misma norma reglamentaria ha venido en cierta manera a compensar la involución en la accesibilidad achacable al legislador, al rebajar el umbral de alturas en que se hará obligatoria la instalación de ascensor a partir del mes de octubre. Parece que al final se ha avanzado en accesibilidad, aunque sea "por la puerta de atrás"35.

En todo caso quedan en el aire importantes interrogantes de índole privada frente al enfoque iuspublicista con que se ha abordado este trabajo; baste aquí evocar las implicaciones en materia de arrendamientos urbanos. Aunque pueda existir una potente línea de subvenciones para las obras sencillas de evolución, los tiempos, ritmos y necesidades de unos y otros no tienen por qué coincidir.

Todo ello en una norma que abiertamente se motiva en la reducción de costes para la construcción de viviendas. No en vano, y por plástica que pueda resultar la noción de viviendas evolutivas en los tiempos del imparable envejecimiento de la población, la nueva regulación se limita a los bloques de vivienda colectiva, y en ningún caso a la unifamiliar cuyos inquilinos, como no puede ser de otra manera, también atraviesan vicisitudes a lo largo de su vida.

\section{BIBLIOGRAFÍA}

P. BATTISTINI, "La loi portant évolution du logement, de l'aménagement et du numérique, dite ELAN, à l'épreuve du Conseil constitutionnel", Les Petites Affiches, 19, 2019, pp. 7-10.

A. BOTO ÁLVAREZ, "Evolución digital y social del urbanismo y la vivienda en Francia: la Ley ELAN de 2018", Revista General de Derecho Administrativo, 51, 2019.

G. DURAND-PASQUIER, "L'incidence de la Loi ELAN sur les normes et les règles de la construction", Revue de droit immobilier, 1, 2019, pp. 8-16.

N. FOULQUIER, "La naturaleza del derecho exigible a una vivienda", Revista institucional de la defensa pública de la Ciudad Autónoma de Buenos Aires, 16, 2018, pp. 40-50. https://www.mpdefensa.gob.ar/publicaciones/derecho-a-la-vivienda-argentina-y-francia

C. MIALOT, "Diez años de la Ley DALO (derecho a la vivienda exigible) en Francia y el contexto europeo", en VV.AA., La ley del derecho a la vivienda de Catalunya: diez años de vigencia. Balance y futuro, Thomson ReutersAranzadi, Cizur Menor, 2018, pp. 59-73.

R. NOGUELLOU, "La Loi ELAN: présentation rapide des dispositions sur le logement", Revue française de droit administratif, 1, 2019, pp. 30-32.

J. RAYNAL, "Droit au logement et accessibilité du cadre bâti aux personnes handicapées", Actualité juridique. Droit immobilier, 3, 2019, pp. 179-185.

\footnotetext{
35 Tras haber sido muy críticos con la Ley, de la que en su momento como ya se ha indicado habían reclamado un régimen más garantista respecto a la instalación de ascensores, el Conseil national consultatif des personnes handicapées (CNCPH) emitió así informe positivo sobre el proyecto de Decreto, en enero de 2019. El texto puede consultarse en https://www.gouvernement.fr/sites/default/files/contenu/piece-jointe/2019/01/avis cncph. dec r3 18jan2019docx.pdf.
} 